\title{
Phosphate solubilization by fungi with nematicidal potential
}

\author{
D. L. Lima-Rivera ${ }^{1}$, D. Lopez-Lima ${ }^{1}$, D. Desgarennes², A. S. Velázquez-Rodríguez ${ }^{1}$, G. \\ Carrion $^{2 *}$ \\ ${ }^{1}$ Universidad Autónoma del Estado de México, Instituto Literario 100, Toluca 50000, Estado de México, \\ Mexico \\ ${ }^{2}$ Instituto de Ecología, A.C., Carretera Antigua a Coatepec 351, Xalapa 91070, Veracruz, Mexico \\ *Corresponding author: gloria.carrion@inecol.mx
}

\begin{abstract}
We evaluated the nematicidal potential and phosphate solubilization ability of the fungal species Geomyces pannorum and Paecilomyces carneus, which are associated with the potato cyst nematode Globodera rostochiensis. In a broth medium containing calcium phosphate, the two fungi solubilized between $67 \%-96 \%$ of the insoluble phosphorus that was present in the medium, and in a broth medium containing iron phosphate, the phosphorus that was solubilized by the two fungi ranged between $2 \%-13 \%$. In a greenhouse experiment, G. pannorum and $P$. carneus were applied to soil that was naturally infested with $G$. rostochiensis and planted with Avena sativa. The fungi increased the available phosphorus in the soil by more than $30 \%$, and Paecilomyces carneus also reduced the nematode population by $71 \%$. This study is the first to report on the ability of G. pannorum and P. carneus to increase the available phosphorus in the soil, suggesting that these fungal species may have potential uses in agricultural soils with insoluble phosphorus. Moreover, this study provides a new alternative that contributes to the sustainable management of crops with bio-agents that have dual activity; they increase the available phosphorus in the soil and mitigate plant parasitic nematodes.
\end{abstract}

Keywords: Phosphorus, filamentous fungi, hydroxyapatite, strengite, Globodera rostochiensis

\section{Introduction}

Plant parasitic nematodes (PPNs) cause serious economic losses to farmers worldwide, at more than US $\$ 157$ billion each year (Abad et al., 2008; Li et al., 2015). In accordance with their feeding mechanism, PPNs are classified into the following three broad groups: migratory ectoparasites (e.g., Belonolaimus spp., Xiphinema spp., and Trichodorus spp.), migratory endoparasites (e.g., Pratylenchus spp. and Radopholus spp.) and sedentary endoparasites (e.g., Meloidogyne spp., or root knot nematodes, and the cyst nematodes Heterodera spp. and Globodera spp.) (Sijmons et al., 1994). Among the PPNs, the 
root knot nematodes and cyst nematodes cause the most crop damage worldwide (Li et al., 2015).

For decades, cyst nematode control has relied primarily on chemical nematicides and on using crop rotation and resistant cultivars as complementary control methods (Chitwood, 2002). However, the effectiveness of these methods has been limited, and crop production is still under heavy threat from cyst nematodes. Additionally, the available chemical nematicides are being withdrawn from use because of their notorious toxicity to wildlife and human health ( $\mathrm{Li}$ et al., 2015). Therefore, there is an urgent need to find novel, ecologically safe and effective management strategies to control cyst nematodes. In this sense, biological control represents an economically and environmentally friendly approach to reducing nematode damage. Some bacteria and nematophagous fungi possess sophisticated strategies for killing nematodes, and they are often targeted to specific developmental stages of the nematode life cycle (Jaffee, 1992).

In fact, several of these nematophagous microbes or their secondary metabolites have been developed as biological control agents (BCAs) (Li et al., 2015). In addition to their nematicidal action, BCAs could improve other characteristics associated with plant development, such as nutrient availability. In this regard, phosphorus (P), an essential element for plant development, is only absorbed by plants in a soluble form, i.e., as orthophosphates $\mathrm{H}_{2} \mathrm{PO}_{4}^{-}$and $\left(\mathrm{HPO}_{4}\right)^{2-}$ (Schachtman et al., 1998; Han et al., 2014). However, under natural conditions, most of the phosphorus in the soil is fixed in poorly soluble mineral forms such as variscite $\mathrm{AlPO}_{4} \cdot 2 \mathrm{H}_{2} \mathrm{O}$, strengite $\mathrm{FePO}_{4} \cdot 2 \mathrm{H}_{2} \mathrm{O}$, apatite $\mathrm{Ca}_{5}\left(\mathrm{PO}_{4}\right)_{3}$, fluorapatite $\mathrm{Ca}_{5}\left(\mathrm{PO}_{4}\right)_{3} \mathrm{~F}$, and hydroxyapatite $\mathrm{Ca}_{5}\left(\mathrm{PO}_{4}\right)_{3} \mathrm{OH}$, which are not available for plant nutrition (Merbach et al., 2010). In addition, between $70 \%-90 \%$ of phosphorus that is applied to the soil as fertilizer is converted into insoluble compounds that cannot be assimilated by plants (Walpola and Yoon,
2012). Several studies have shown that bacteria (Schoebitz et al., 2013) and some species of the fungi Aspergillus, Paecilomyces, and Penicillium, among others, have the capacity to solubilize insoluble inorganic phosphates (Chuang et al., 2007, Yasser et al., 2014). Some nematophagous fungi, such as Arthrobotrys oligospora and Purpureocillium lilacinum (=Paecilomyces lilacinus), have also shown mineralsolubilizing abilities (Duponnois et al., 2006; Hernandez-Leal et al., 2011). In recent years, several studies have focused on the characterization and evaluation of mineral-solubilizing microorganisms with the aim of incorporating them into sustainable agricultural management strategies (Sharma et al., 2013; Yin et al., 2015; Fu et al., 2016; Zúñiga-Silva et al., 2016). Considering the importance of BCAs with dual activity (biocontrol and mineral solubilization), the goals of this study were to evaluate the nematicidal potential and phosphate solubilization capacity of two fungi associated with the potato cyst nematode (PCN) Globodera rostochiensis.

\section{Materials and Methods}

\subsection{Fungal strains}

The two fungi used in our study, namely Geomyces pannorum and Paecilomyces carneus, were isolated from the PCN Globodera rostochiensis. The G. rostochiensis nematodes were obtained from the rhizosphere of potato crops growing in the mountainous region of Veracruz State, Mexico. Geomyces pannorum (IE-449) was isolated from the cyst stage, whereas Paecilomyces carneus (IE-431) was isolated from the J2 juvenile stage of $G$. rostochiensis. Both fungi were cultivated on oatmeal agar at $22{ }^{\circ} \mathrm{C}$ and have been deposited in the culture collection of the Instituto de Ecología A.C. (World Federation Culture Collection No. IEWDCM 782). The Paecilomyces carneus strain 
is also deposited in the Bank of Microbial Genetic Resources of the Agricultural Research Institute of Chile.

\subsection{Screening for phosphate solubilization capacity}

To determine the solubilization capacity of $G$. $p a$ norum and $P$. carneus, the modified culture medium Pikovskaya agar (MP) was used (Nopparat et al., 2009). This medium indicates the phosphate-solubilizing capacity by forming a clear halo around the mycelium (Sundara and Sinha, 1963). The MP was composed of $0.5 \mathrm{~g}$ of ammonium sulfate $\left(\left(\mathrm{NH}_{4}\right)_{2} \mathrm{SO}_{4}\right), 0.2$ $\mathrm{g}$ of potassium chloride $(\mathrm{KCl}), 0.1 \mathrm{~g}$ of magnesium sulfate $\left(\mathrm{MgSO}_{4}-7 \mathrm{H}_{2} \mathrm{O}\right), 0.004 \mathrm{~g}$ of manganese sulfate $\left(\mathrm{MnSO}_{4}-\mathrm{H}_{2} \mathrm{O}\right), 0.002 \mathrm{~g}$ of iron sulfate $\left(\mathrm{FeSO}_{4}-7 \mathrm{H}_{2} \mathrm{O}\right)$, $0.2 \mathrm{~g}$ of sodium chloride $(\mathrm{NaCl}), 10 \mathrm{~g}$ of D-glucose (Sigma-Aldrich), $0.5 \mathrm{~g}$ of yeast extract (Bioxon), 0.5 $\mathrm{g}$ of chloramphenicol (Pfizer), $18 \mathrm{~g}$ of agar (Bioxon), and $900 \mathrm{ml}$ of water. Additionally, $0.2 \mathrm{~g}$ of rose bengal $\mathrm{L}^{-1} \mathrm{MP}$ was added to visualize the solubilization halo. Simultaneously, two solutions with insoluble phosphates were prepared with $0.5 \mathrm{~g}$ of either calcium phosphate (hydroxyapatite, $\mathrm{Ca}_{5}\left(\mathrm{PO}_{4}\right)_{3} \mathrm{OH}$, Quimica Meyer) or iron phosphate (strengite $\mathrm{FePO}_{4} \cdot 2 \mathrm{H}_{2} \mathrm{O}$, Quimica Barquim), which was combined with $5 \mathrm{~g}$ of gum arabic (Kremer) and water (100 ml). The MP and phosphate solutions were sterilized separately by autoclaving them at $121^{\circ} \mathrm{C}$ and 22 psi for 15 minutes. These solutions were subsequently mixed and poured into Petri dishes ( $9 \mathrm{~cm}$ in diameter), which were inoculated at the centers with spores from each fungus (with 10 replicates per fungus). The dishes were incubated at $25^{\circ} \mathrm{C}$, and the diameter of the colony and the halo that formed around each one was measured along two axes. Measurements were taken every two days after inoculation until the fungi ceased to grow (at day 16 for the medium with calcium phosphate, and day 20 for the medium with iron phosphate). To determine the extent of fungal activity on the substrate relative to the size of the colony, we calculated the solubilization index (SI) (Morales et al., 2011). The SI was recorded on each measurement day and was calculated as follows:

$$
\mathrm{SI}=\frac{\text { Diameter of the halo in the medium }}{\text { Colony diameter }}
$$

In addition, the $\mathrm{pH}$ of the agar plates was measured using $\mathrm{pH}$ indicator strips (AP, PI Model 1015), both before fungal inoculation and at the end of the experiment.

\subsection{Quantitative estimation of phosphate solubilization in broth culture}

The quantitative evaluation of the phosphorus solubilized by fungi was performed using modified Pikovskaya broth (PB) to which hydroxyapatite (calcium phosphate) or strengite (iron phosphate) was added, but there was no agar or rose bengal. Flasks (500 mL capacity) containing $250 \mathrm{~mL}$ of PB were inoculated with three disks of agar ( $5 \mathrm{~mm}$ diameter) that had been taken from pure cultures of G. pannorum and P. carneus (for three replicates of each fungus/ phosphate type). Flasks with the same aliquots of a sterilized, uninoculated PB medium were used as a control (three replicates). The total $\mathrm{P}$ in flasks containing PB supplemented with calcium phosphate was $108.95 \mathrm{mg} \mathrm{L}^{-1}$, and the initial concentration of soluble $\mathrm{P}$ was $18.99 \pm 2.34 \mathrm{mg} \mathrm{L}^{-1}$ (insoluble $\mathrm{P}=89.95$ $\pm 2.22 \mathrm{mg} \mathrm{L}^{-1}$ ) with a $\mathrm{pH}$ of $6.3 \pm 0.12$. In the flasks containing PB supplemented with iron phosphate, the total $\mathrm{P}$ was $108.05 \mathrm{mg} \mathrm{L}^{-1}$, and the initial amount of soluble $\mathrm{P}$ was $1.63 \pm 0.13 \mathrm{mg} \mathrm{L}^{-1}$ (insoluble $\mathrm{P}=$ $\left.106.41 \pm 0.09 \mathrm{mg} \mathrm{L}^{-1}\right)$ with a $\mathrm{pH}$ of $3.76 \pm 0.08$. All the flasks were incubated at room temperature $\left(22^{\circ} \mathrm{C}\right)$ 
on a mechanical shaker (Lab-Line 3520) at $130 \mathrm{rpm}$ for 18 days. Ten milliliters of supernatant were aseptically removed from each flask, before introducing the fungi, and then the removal was repeated at twoday intervals after inoculation. To eliminate the mycelium, the extracts were passed through filter paper (Whatman No. 42) that had previously been sterilized. The soluble phosphorus in the resulting filtrates was quantified by the colorimetry of the molybdophosphoric complexes that were reduced with ascorbic acid, which were then measured at $880 \mathrm{~nm}$ using a spectrophotometer Genesys 20, ThermoSpectronic (Chuang et al., 2007). The initial concentration of insoluble $\mathrm{P}$ in the medium (before inoculation) was used as a reference to quantify the amounts of $\mathrm{P}$ solubilized by the fungi. The results are shown as the average of the three replicates, in $\mathrm{mg} \mathrm{L}^{-1}$. In considering that efficient phosphate-solubilizing microorganisms tend to decrease the medium $\mathrm{pH}$ during their growth (Sharma et al., 2013; Li et al., 2016), we decided to determine the $\mathrm{pH}$ of the filtrate for each sample using a potentiometer (Conductronic PC45).

\subsection{Nematicidal potential and phosphorus availability in soil}

To assess the G. pannorum and $P$. carneus nematicidal potential and their capacity to increase the available phosphorus in the soil, we conducted a greenhouse experiment with Avena sativa (oat) plants growing in soil that was naturally infested with $G$. rostochiensis. The soil was collected from potato fields in Veracruz State, and it showed a G. rostochiensis infestation level between 7.1 and 15.4 eggs $g$ soil $^{-1}$. The soil physical and chemical characteristics are shown in Table 1. Although A. sativa is not a G. rostochiensis host, it is commonly used as a rotation crop in fields infested with this nematode (Sullivan et al., 2007). Avena sati$v a$ seeds were placed on an inert substrate to promote germination, and after 20 days, the plants were moved in pairs into 2-L capacity pots that were filled with previously homogenized and sieved (to $3 \mathrm{~mm}$ ) soil. Three treatments were compared, namely G. pannorum inoculation $\left(2 \times 10^{9}\right.$ spores per pot), P. carneus inoculation ( $2 \times 10^{9}$ spores per pot), and no inoculation (as a control). The fungal spores were obtained from two-week-old pure oat-agar cultures; the spores were dissolved in $200 \mathrm{~mL}$ of sterile distilled water and applied around the oat plants in each pot. The pots were placed in a greenhouse with natural light and an average temperature of $30^{\circ} \mathrm{C}$, and they were arranged in a completely randomized design with five replicates per treatment. After 3 months, the plants were removed from the pots, and the final nematode population and the phosphorus availability were measured. Potato cyst nematodes were obtained using the Fenwick can technique, and the number of viable eggs and juveniles $\mathrm{J} 2$ per cyst was counted to calculate the infestation level (eggs g soil-1). The available phosphorus in the soil was extracted according to Bray and Kurtz (1945), and it was quantified by colorimetric test as previously described (Chuang et al., 2007). In addition, the $\mathrm{C}, \mathrm{N}, \mathrm{K}, \mathrm{Ca}, \mathrm{Mg}$, and $\mathrm{Fe}$ contents in the soil as well as plant biomass parameters (heights, fresh weights, dry weights and numbers of seeds) were measured at the end of the experiment. 
Table 1. Physico-chemical characteristics of the soil that was used in the greenhouse experiment prior to fungi inoculation.

\begin{tabular}{|c|c|c|}
\hline Soil parameters & Amount & Quantification technique \\
\hline \% Clay & 15 & \\
\hline$\%$ Silt & 28 & Bouyoucos \\
\hline$\%$ Sand & 57 & \\
\hline pH & $4.38 \pm 0.05$ & 1:2 water reaction (Conductronic $\mathrm{PC} 45 \mathrm{pH}$ meter) \\
\hline$\% \mathrm{OM}$ & $6.90 \pm 0.17$ & C/N Analyzer TruSpec (LECO) \\
\hline $\mathbf{N}\left(\mathrm{mg} \mathrm{kg}^{-1}\right)$ & $19.9 \pm 0.1$ & Potassium chloride extraction and steam dragging distillation \\
\hline Available $P\left(\mathrm{mg} \mathrm{kg}^{-1}\right)$ & $8.45 \pm 0.05$ & Bray and Kurtz 1 \\
\hline $\mathrm{K}\left(\mathrm{cmol} \mathrm{kg}^{-1}\right)$ & $0.61 \pm 0.0$ & $\begin{array}{l}\text { Ammonium acetate extraction and quantification by flame } \\
\text { photometry }\end{array}$ \\
\hline $\mathrm{Ca}\left(\mathrm{cmol} \mathrm{kg}^{-1}\right)$ & $2.73 \pm 0.12$ & Ammonium acetate extraction and quantification by atomic \\
\hline $\operatorname{Mg}\left(\mathbf{c m o l ~ k g}^{-1}\right)$ & $0.26 \pm 0.0$ & absorption \\
\hline $\mathrm{Fe}\left(\mathrm{mg} \mathrm{kg}^{-1}\right)$ & $15.95 \pm 0.05$ & $\begin{array}{l}\text { Diethylenetriaminepentaacetic acid extraction and quantification by } \\
\qquad \text { atomic absorption }\end{array}$ \\
\hline$\% \mathrm{OM}$ & $6.9 \pm 0.01$ & $\begin{array}{c}\text { Calculated by taking the } \% \text { of } \mathrm{C} \text { and the Van Bemmelen correlation } \\
\text { factor }\end{array}$ \\
\hline
\end{tabular}

\subsection{Statistical analysis}

Shapiro-Wilks and Levene tests indicated that the results did not satisfy the normality and homogeneity of the variance assumptions, respectively. Therefore, to assess the differences between the treatments, the data obtained for SI in the MP medium was subjected to a Mann-Whitney test, and the phosphorus levels in the PB medium, along with the nematode infestation level, phosphorus availability in soil, soil characteristic and plant biomass parameters, were subjected to a Kruskal-Wallis test. When the Kruskal-Wallis test was significant, a Nemenyi post-hoc test was performed to determine which levels of the independent variable 
differed from every other level. Likewise, to determine if there was a significant correlation between the $\mathrm{pH}$ values and the amount of $\mathrm{P}$ solubilized in the liquid medium, we performed a Pearson's correlation test. All the statistical analyses were performed in $\mathrm{R}$ (R Core Team, 2013).

\section{Results}

\subsection{Calcium and iron phosphate solubilization index}

The two fungi studied here produced similar solubilization halos in MP medium supplemented with hydroxyapatite and strengite; in fact, the SI value was not significantly different between the two fungi. In MP-hydroxyapatite medium, G. pannorum and P. carneus formed a solubilization halo on the sixth day after inoculation, with SI values of 0.59 and 0.49 , respectively (Figure 1a). The maximum values obtained for G. pannorum and $P$. carneus appeared on day 16 after inoculation, with SI values of $1.95(\mathrm{pH}=5.1)$ and $2.10(\mathrm{pH}$ =4.4), respectively (Figure 1a). However, in MPstrengite medium, the mycelial growth was quantified from the sixth day after inoculation for both fungi. Geomyces pannorum and P. carneus began their halo formation until day 12 with SI values of 0.57 and 1.02, respectively (Figure 1b). For both fungi, the growth of mycelium and the halo formation had ceased by day 14 after inoculation. At the same day, the highest SI values were recorded for G. pannorum at $0.92(\mathrm{pH}=3.2)$ and for P. carneus at $1.12(\mathrm{pH}=3.1)$ (Figure 1b).

\subsection{Calcium and iron phosphate solubilization and $\mathrm{pH}$ measurements in broth medium}

Hydroxyapatite (calcium phosphate) was solubilized by the two evaluated fungi, solubilizing from the second day after inoculation in the PB medium. Geomyces pannorum reached its maximum solubilization level at day 16 after inoculation with 71.44 $\mathrm{mg} \mathrm{L}^{-1}$ of solubilized $\mathrm{P}$, representing $79 \%$ of the insoluble $\mathrm{P}$ at the start of the test (initial concentration of insoluble $\mathrm{P}=89.95 \pm 2.22 \mathrm{mg} \mathrm{L}^{-1}$ ) (Figure 2a). By contrast, P. carneus reached its maximum solubilization level at day 18 with $83.2 \mathrm{mg} \mathrm{L}^{-1}$ of solubilized $\mathrm{P}$, which represented $96 \%$ of the insoluble $\mathrm{P}$ in the medium at the beginning of the test (Figure 2a). The amount of soluble P in the PB medium of the control remained constant $(1.87 \pm 1.80$ $\left.\mathrm{mg} \mathrm{L}^{-1}\right)$ throughout the experiment and was significantly lower $(H=55.596, \mathrm{P}=2.3 \mathrm{e}-12)$ than the soluble $\mathrm{P}$ that was quantified in the medium of the two fungi (Figure 2a). Additionally, we observed that the $\mathrm{P}$ solubilization increase was accompanied by a reduction in the $\mathrm{pH}$ of the $\mathrm{PB}$ medium in the two fungal treatments (Figures $2 \mathrm{a}-2 \mathrm{~b}$ ). We performed $\mathrm{a}$ Pearson's correlation test for these two variables, which was significant for both G. pannorum $(R=$ $0.686, \mathrm{P}=2.807 \mathrm{e}-05)$, and $P$. carneus $(R=0.847$, $\mathrm{P}=3.687 \mathrm{e}-09)$. By contrast, the $\mathrm{pH}$ in the $\mathrm{PB}$ control medium was stable throughout the experiment $(6.41 \pm 0.2)$ (Figure 2b). 

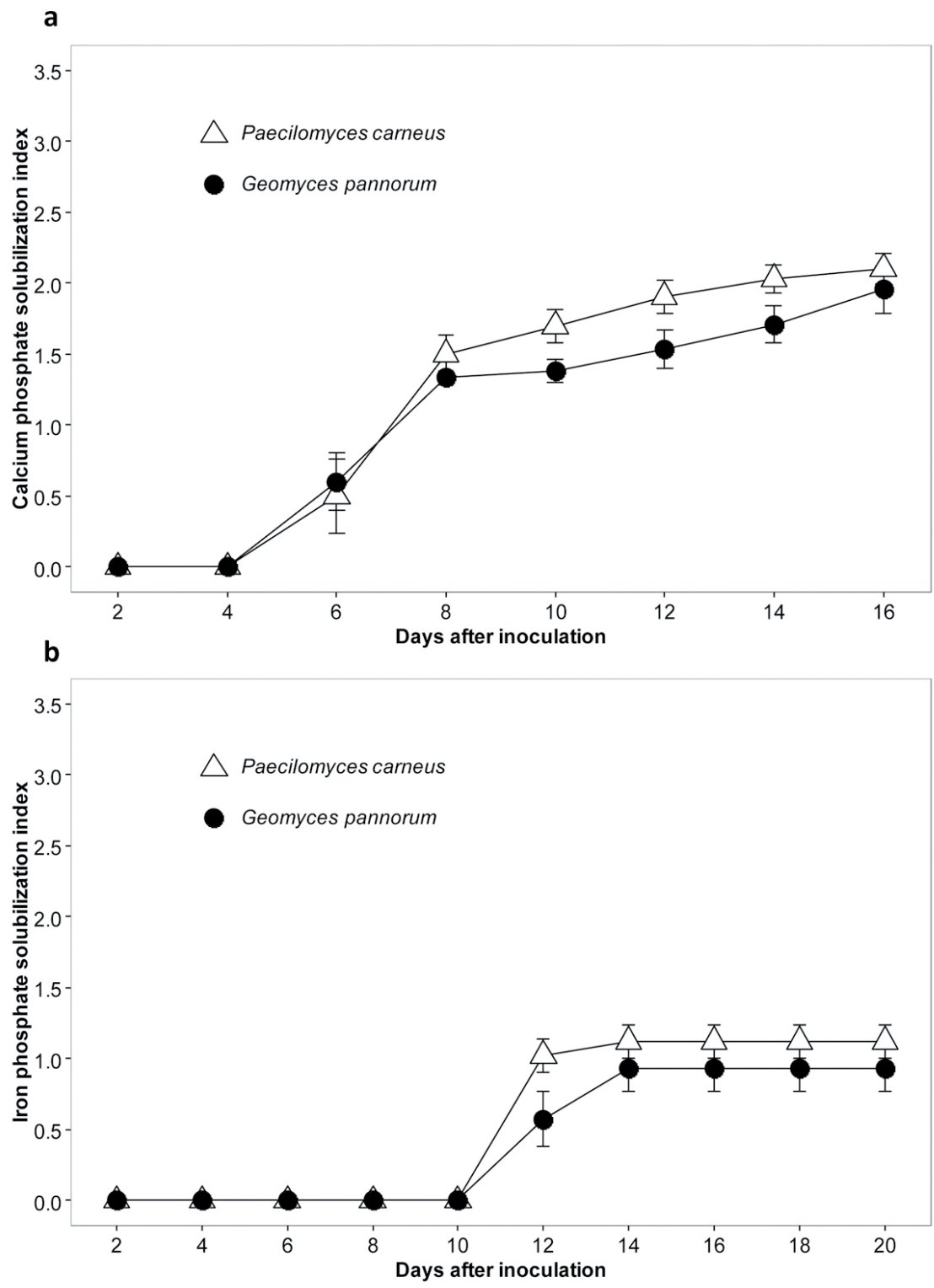

Figure 1. Phosphate solubilization index of Geomyces pannorum and Paecilomyces carneus in MP medium with (a) tribasic calcium phosphate (hydroxyapatite) and (b) iron phosphate (strengite). Each data point represents the average for 10 replicates. 


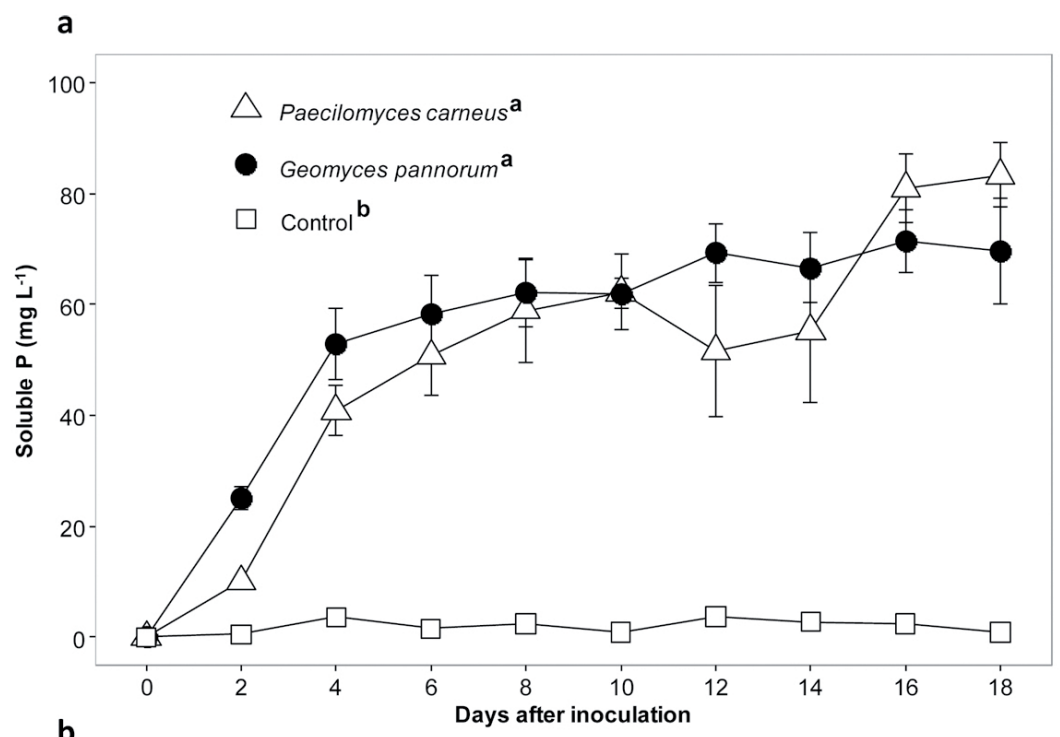

b

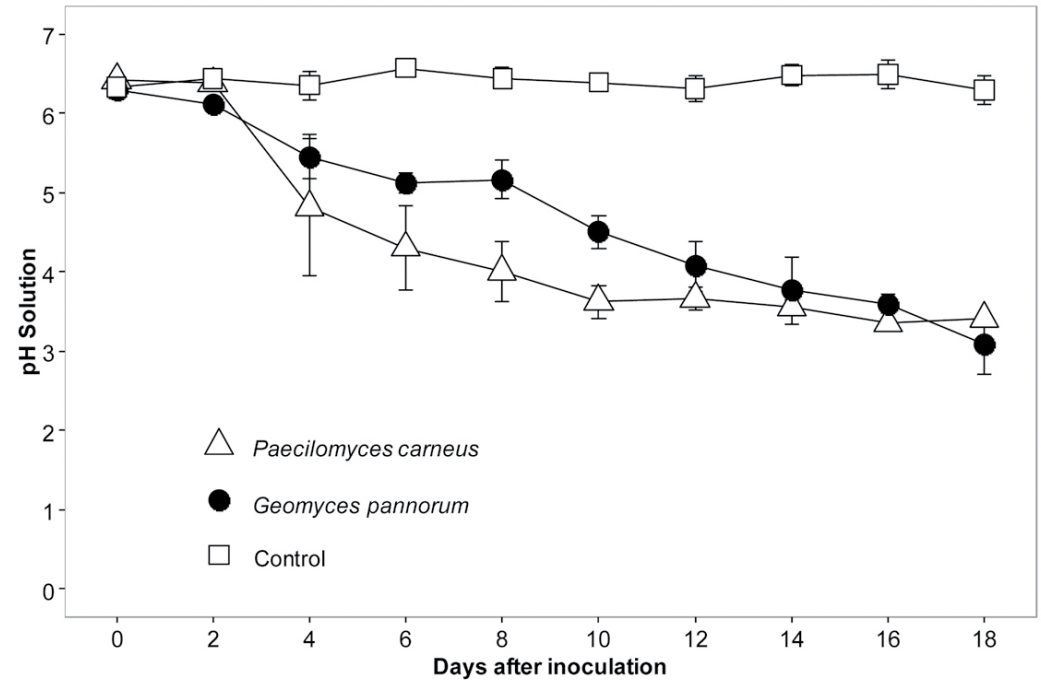

Figure 2. Effect of Geomyces pannorum and Paecilomyces carneus on phosphate solubilization (a) and $\mathrm{pH}$ (b), in PB medium supplemented with tribasic calcium phosphate (hydroxyapatite). Each data point represents the average of three replicates. In phosphate solubilization panel (a), distinct letters indicate significant differences between treatments according to the Nemenyi post-hoc test, following a Kruskal-Wallis test. 
With respect to strengite (iron phosphate) solubilization, G. pannorum and P. carneus had the highest solubilization levels on day six after inoculation in the PB medium. Geomyces pannorum solubilized $14.35 \mathrm{mg} \mathrm{L}^{-1}$ of $\mathrm{P}$, which represented $13 \%$ of the total insoluble $\mathrm{P}$ from the beginning of the experiment $\left(106.41 \pm 0.09 \mathrm{mg} \mathrm{L}^{-1}\right)$. The phosphorus that was solubilized by $G$. pannorum was significantly $(H=20.766, \mathrm{P}=3.096 \mathrm{e}-05)$ greater than the $P$ solubilized in either $P$. carneus $\left(2.08 \mathrm{mg} \mathrm{L}^{-1}, 2 \%\right.$ of the insoluble $\mathrm{P}$ at the beginning of the test) or the control (no P solubilized) (Figure 3a). Between days 12 and 18 following inoculation, no activity was detected for $\mathrm{P}$ solubilization in the medium (Figure 3a). Both fungi reduced the $\mathrm{pH}$ of the $\mathrm{PB}$ medium over the experiment, reaching $\mathrm{pH}$ values of 2.71 for G. pannorum and 2.66 for $P$. carneus (Figure 3b). However, no significant correlation was observed between the decreasing $\mathrm{pH}$ and the amount of solubilized P. By contrast, the $\mathrm{pH}$ of the control medium only exhibited a slight decrease from 3.9 to 3.7 (Figure $3 b$ ).
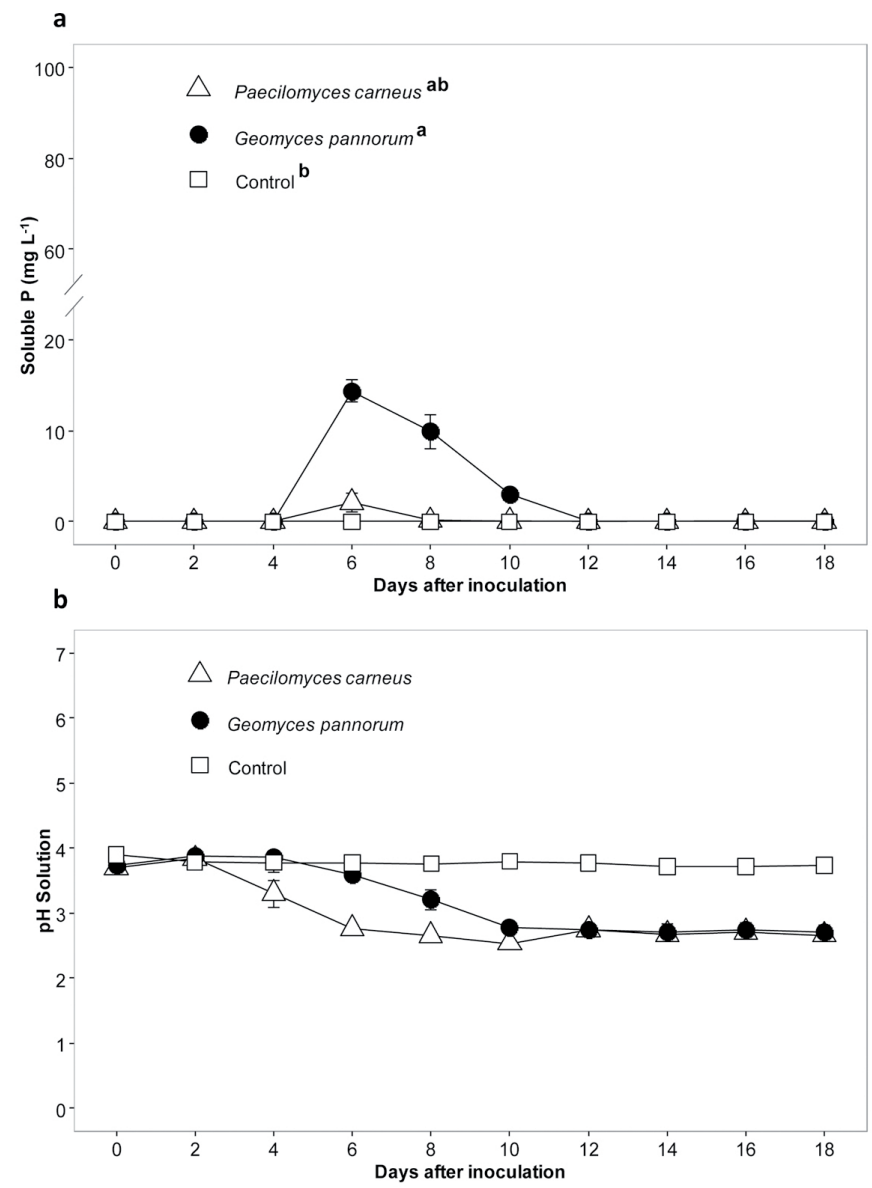

Figure 3. Effect of Geomyces pannorum and Paecilomyces carneus on phosphate solubilization (a) and pH (b) in PB medium supplemented with iron phosphate (strengite). Each data point represents the average of three replicates. In phosphate solubilization panel (a), distinct letters indicate significant differences between treatments according to the Nemenyi post-hoc test, after a Kruskal-Wallis test. 
3.3. Nematicidal potential and available phosphorus in soil

The Geomyces pannorum and P. carneus nematicidal potential effect was assessed in relation to the number of viable $G$. rostochiensis eggs present in the soil (nematode infestation level), in a greenhouse experiment with oat plants. Paecilomyces carneus caused a $71.3 \%$ reduction in the final nematode infestation

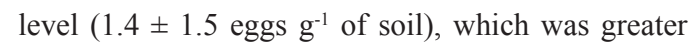
than the $39.4 \%$ reduction observed for the G. pannorum treatment $\left(4.4 \pm 1.6\right.$ eggs g-1 $^{-1}$ of soil) (Figure 4). Although both fungi reduced the nematode infestation level, only the reduction caused by $P$. carneus was significantly different $(H=11.834, \mathrm{P}=0.002694)$ from that of the control treatment, in which similar initial and final nematode infestation levels were recorded (Table 2, Figure 4).

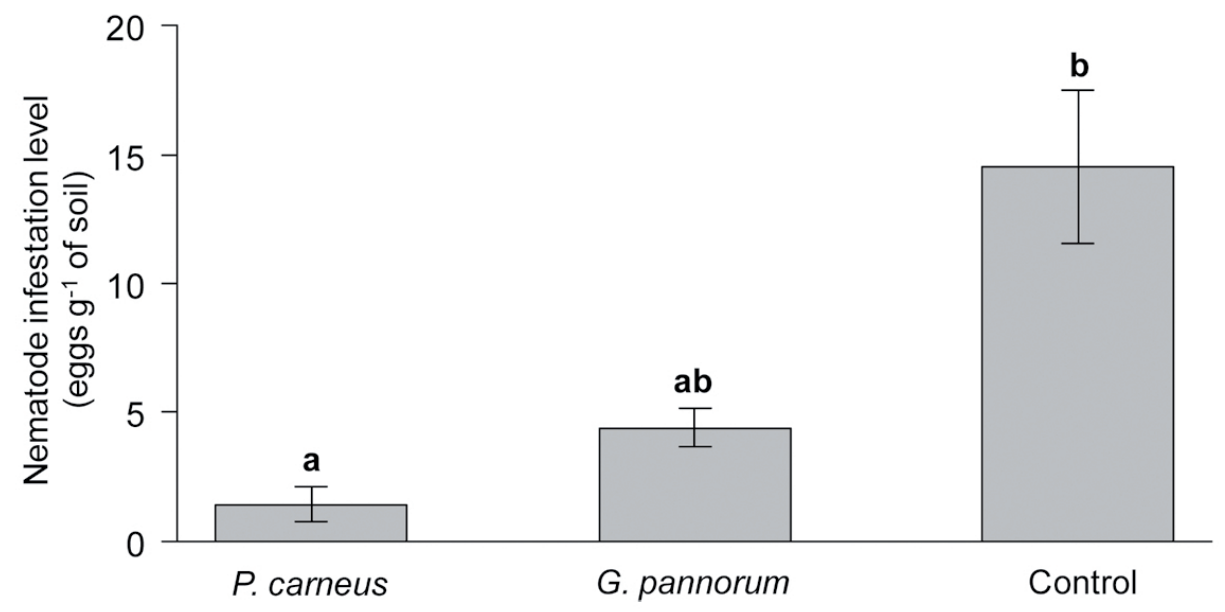

Figure 4. Effect of Geomyces pannorum and Paecilomyces carneus on the nematode infestation level in the soil at the end of the greenhouse experiment. Distinct letters indicate significant differences between treatments according to the Nemenyi post-hoc test, after a Kruskal-Wallis test. 
Table 2. Avena sativa biomass parameters and Globodera rostochiensis infestation level.

\begin{tabular}{clclclc}
\hline Treatments & $\begin{array}{l}\text { Height } \\
(\mathbf{c m})\end{array}$ & $\begin{array}{c}\text { Dry weight } \\
(\mathbf{g})\end{array}$ & $\begin{array}{l}\text { Seeds } \\
\text { number }\end{array}$ & $\begin{array}{c}\text { Initial } \\
\text { NIL }\end{array}$ & Final & $\begin{array}{l}\text { NIL } \\
\text { Nematode } \\
\% \\
\text { reduction }\end{array}$ \\
\hline $\begin{array}{c}\text { Geomyces } \\
\text { pannorum }\end{array}$ & $60.7 \pm 7.1$ & $0.83 \pm 0.22$ & $8.4 \pm 2.6$ & $8.7 \pm 3.0$ & $4.4 \pm 1.6 \mathrm{ab}$ & 39.4 \\
$\begin{array}{c}\text { Paecilomyces } \\
\text { carneus }\end{array}$ & $63.7 \pm 8.8$ & $0.81 \pm 0.29$ & $9.8 \pm 2.4$ & $7.1 \pm 4.6$ & $1.4 \pm 1.5 \mathrm{a}$ & 71.3 \\
Control & $62 \pm 10.7$ & $0.90 \pm 0.25$ & $8.8 \pm 3.0$ & $15.4 \pm 11.7$ & $14.5 \pm 6.6 \mathrm{~b}$ & 0 \\
$\boldsymbol{H}^{(\mathrm{b})}$ & 0.76 & 1.24 & 2.20 & 3.7 & 11.3 & -- \\
P & 0.6838 & 0.53 & .3327 & 0.15 & 0.01 & - \\
\hline
\end{tabular}

(a) Nematode infestation level (eggs g-1 of soil). ${ }^{(b)} H=$ Kruskal-Wallis test. "Distinct letters indicate significant differences between treatments according to the Nemenyi post-hoc test. The nematode percentage of the reduction was calculated on the basis of the initial and final nematode infestation level in the five replicates for each treatment.

With regards to the phosphorus availability in the soil, in comparison with the initial available $\mathrm{P}$ values, we observed an increase in the available $\mathrm{P}$ in the pots that were inoculated with fungi at the end of the experiment (Table 3, Figure 5). We observed a $47.5 \%$ increase in available $\mathrm{P}$ in the soil with the $P$. carneus treatment, and a $35.4 \%$ increase was observed for the G. pannorum treatment (Figure 5). However, only the P. carneus treatment was significantly higher $(H=5.95, \mathrm{P}=0.050)$ than the control, which showed an increase of $6.6 \%$ over the initial available phosphorus (Figure 5).
In addition to the available $\mathrm{P}$, we measured other soil fertility parameters, but only the organic matter and Fe content were significantly different between the fungi treatments and the control (Table 3).

Finally, we wondered if plant biomass parameters such as the height, dry weight and seed number were affected by G. pannorum and $P$. carneus inoculation in comparison with the control. Although we observed slightly different plant biomass values between the fungal treatments and the control, no significant differences were recorded (Table 2). 
Table 3. Soil characteristics ( \pm standard deviation) at the end of the greenhouse experiment.

\begin{tabular}{|c|c|c|c|c|c|}
\hline \multirow{2}{*}{ Parameter } & \multicolumn{3}{|c|}{ Final values } & \multicolumn{2}{|c|}{ Statistics } \\
\hline & G. pannorum & P. carneus & Control & $\boldsymbol{H}^{(\mathrm{a})}$ & $P$ value \\
\hline pH & $4.89 \pm 0.05$ & $4.89 \pm 0.03$ & $4.74 \pm 0.01$ & 5.42 & 0.066 \\
\hline$\% \mathrm{OM}$ & $7.67 \pm 0.39 \mathbf{a}^{\dagger}$ & $7.33 \pm 0.25 \mathbf{a b}$ & $6.81 \pm 0.25 \mathbf{b}$ & 6.34 & 0.037 \\
\hline $\mathbf{N}\left(\mathrm{mg} \mathrm{kg}^{-1}\right)$ & $9.09 \pm 2.75$ & $8.53 \pm 1.4$ & $9.5 \pm 4.25$ & 5.42 & 0.066 \\
\hline Available $P\left(\mathrm{mg} \mathrm{kg}^{-1}\right)$ & $11.44 \pm 0.33 \mathbf{a b}$ & $12.46 \pm 1.21 \mathbf{a}$ & $9.01 \pm 0.33 \mathbf{b}$ & 5.95 & 0.050 \\
\hline $\mathrm{K}\left(\mathrm{cmol} \mathrm{kg}^{-1}\right)$ & $0.52 \pm 0.02$ & $0.52 \pm 0.0$ & $0.47 \pm 0.0$ & 5.89 & 0.052 \\
\hline $\mathrm{Ca}\left(\mathrm{cmol} \mathrm{kg}^{-1}\right)$ & $2.10 \pm 0.01$ & $2.24 \pm 0.14$ & $2.14 \pm 0.14$ & 1.42 & 0.491 \\
\hline $\operatorname{Mg}\left(\mathrm{cmol} \mathrm{kg}^{-1}\right)$ & $0.12 \pm 0.01$ & $0.14 \pm 0.03$ & $0.15 \pm 0.03$ & 1.91 & 0.383 \\
\hline $\mathrm{Fe}\left(\mathrm{mg} \mathrm{kg}^{-1}\right)$ & $14.35 \pm 0.25 \mathbf{a}$ & $14.66 \pm 0.13 \mathbf{a b}$ & $15.85 \pm 0.45 \mathbf{b}$ & 6.48 & 0.039 \\
\hline
\end{tabular}
(a) $H=$ Kruskal-Wallis test. 'Distinct letters indicate significant differences between treatments according to the Nemenyi post-
hoc test.

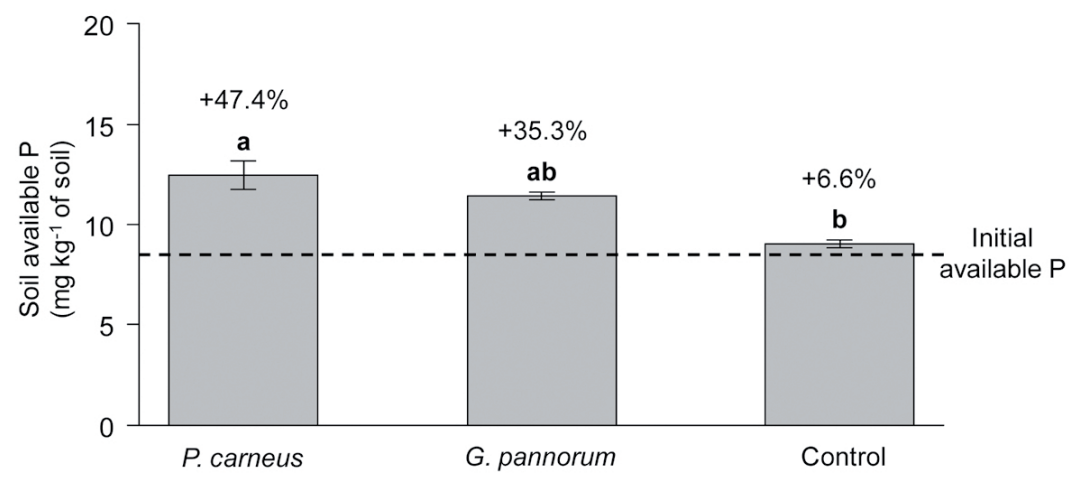

Figure 5 Effect of Geomyces pannorum and Paecilomyces carneus on available $\mathrm{P}$ in the soil at the end of the greenhouse experiment. Distinct letters indicate significant differences between treatments according to the Nemenyi post-hoc test, following a Kruskal-Wallis test. The dotted line represents the initial available P in the soil. The numbers above the columns represent the percentage of the increase that occurred between the initial and final soil available P. 


\section{Discussion}

The two fungi exhibited a clear halo around the colony in the MP medium containing calcium phosphate. The SI values obtained for the two fungi tested here are similar to those of Aspergillus, Trichoderma, Penicillium and Paecilomyces strains. Their SI range is between 1.5 and 2 for a medium containing dicalcium phosphate dihydrate $\mathrm{CaHPO}_{4} \cdot 2 \mathrm{H}_{2} \mathrm{O}$ (brushite), which is a less stable mineral than that used in our experiment (Vera et al., 2002). Similarly, in a Pikovskaya agar medium containing tricalcium phosphate $\mathrm{Ca}_{3}\left(\mathrm{PO}_{4}\right)_{2}$, SI values of up to 2.4 have been recorded for Aspergillus niger, with values of 3.1 for Penicillium italicum and 3.0 for Paecilomyces lilacinus (E1Azouni, 2008; Hernandez-Leal et al., 2011). Recently, the solubilization capacity of a Paecilomyces carneus strain that was isolated from a forest soil in Brazil was shown, from which an SI of 1.2 was obtained in a Pikovskaya agar medium containing tricalcium phosphate (Gudiño et al., 2015). The use of compounds such as brushite and tricalcium phosphate for the evaluation of the solubilizing capacity of an organism complicates the measurement of solubilization because these molecules are less stable than the hydroxyapatite used in our study (Bashan et al., 2013).

The clear halo that formed around the mycelium in MP medium with iron phosphate indicates that $G$. pannorum and $P$. carneus also showed solubilization activity in this type of medium. These results are consistent with other studies in which the formation of a clear halo around the mycelium of Paecilomyces spp. isolates was recorded in a medium similar to that used in our experiments (Vera et al., 2002; HernandezLeal et al., 2011). Nonetheless, in some cases, clear halo formation in the solid medium with iron phosphate is not related to the ability of fungi to solubilize (Whitelaw, 1999). Therefore, it is preferable to use a liquid medium with the purpose of clarifying the iron phosphate solubilization capacity of fungi (Whitelaw, 1999).

Likewise, the P quantity that was solubilized in PB medium by the fungi tested in our study is comparable to the P solubilized in a liquid medium with phosphate rock with other fungi such as Penicillium bilaiae (101.7 $\left.\mathrm{mg} \mathrm{L}^{-1}\right)$, P. simplicissimum (58.8 $\left.\mathrm{mg} \mathrm{L}^{-1}\right), P$. griseofulvum (56.1 $\mathrm{mg} \mathrm{L}^{-1}$ ) and P. radicum $(43.3 \mathrm{mg}$ $\mathrm{L}^{-1}$ ) (Wakelin et al., 2004). In fact, Penicillium bilaiae and $P$. radicum are currently used as biofertilizers. However, the decrease of soluble P in the PB medium with iron phosphate (strengite) that was recorded in our study could be associated with $\mathrm{P}$ absorption by fungal mycelia because of their development and related metabolic processes. These results are supported by other studies in which the greatest percentage of solubilization in the medium was recorded at day seven after inoculation with fungi such as Aspergillus (84 $\mu \mathrm{g} \mathrm{ml}^{-1}$ ) and Penicillium ( $\left.81 \mu \mathrm{g} \mathrm{ml}^{-1}\right)$, and the $\mathrm{P}$ concentrations in the medium decreased thereafter (Hernandez-Leal et al., 2011; Coutinho et al., 2012). However, it is possible that the $\mathrm{P}$ that was retained in the mycelium is available for uptake by plant roots when the mycelium dies (Kapri and Tewari, 2010). Future studies should focus on understanding the balance between phosphorus that is solubilized and phosphorus that is absorbed by the fungi for their metabolism and to consider phosphorus uptake by plants. In general, the solubilization of iron phosphate (strengite) in this study was low in comparison with the calcium phosphate (hydroxyapatite). Previous studies have indicated that iron phosphate compounds are less susceptible to microbial solubilization than calcium phosphates (Rinu et al., 2013).

The low $\mathrm{pH}$ of the solid and liquid media that were inoculated with fungi in comparison with the control indicates the release of the acidic substances produced by these microorganisms. Some studies have suggested that the microorganisms that tend to decrease the 
$\mathrm{pH}$ of the medium during growth are efficient phosphate solubilizers (Nahas, 1996; Li et al., 2016). In our study, the $\mathrm{pH}$ was decreased in inverse proportion to the increase in soluble $\mathrm{P}$ in the two fungi grown in PB medium with hydroxyapatite. Similar results were obtained with different strains of Penicillium and $A s-$ pergillus, in which the $\mathrm{pH}$ decrease coincided with the increased solubilization of tricalcium phosphate (Pandey et al., 2008, Li et al., 2016). However, in the $\mathrm{PB}$ medium containing strengite, the most acidic $\mathrm{pH}$ did not coincide with increased levels of solubilization. This finding may indicate that the production of organic acids is not the only mechanism for iron phosphate solubilization. Some microorganisms are able to solubilize P from inorganic compounds by simply lowering the $\mathrm{pH}$, which occurs as a result of fungal metabolism and promotes the solubility of some highly soluble phosphate compounds (Barroso and Nahas, 2005; Sharma et al., 2013; Li et al., 2016). Likewise, most of the microorganisms that are thought to act as solubilizers have the ability to solubilize low-stability phosphate compounds such as brushite, anhydrous dicalcium phosphate $\mathrm{CaHPO}_{4}$ (monetite), octacalcium phosphate $\mathrm{Ca}_{8} \mathrm{H}_{2}\left(\mathrm{PO}_{4}\right)_{6} \cdot 5 \mathrm{H}_{2} \mathrm{O}$ and tricalcium phosphate, but only some are able to solubilize insoluble phosphate compounds such as hydroxyapatite, fluorapatite, strengite and variscite (Dorozhkin, 2011; Khan et al., 2014). Because these compounds are hard insoluble P sources, in vitro testing with a culture that includes these compounds is one of the first steps in the selection of microorganisms with a solubilizing capacity (Bashan et al., 2013). The level of solubilization of hard insoluble $\mathrm{P}$ compounds may depend on other factors, notably the production of enzymes, the availability of a carbon source that can be assimilated and the secretion of strongly chelating organic acids (Wakelin et al., 2004; Vyas et al., 2007). In our study, we used hard insoluble P sources (hydroxyapatite and strengite), which provided a reliable indicator of the solubilization activity of G. pannorum and P. carneus and suggests that these fungal species have greater potential for $\mathrm{P}$ solubilization in the soil.

In our study, the increase in available $P$ in the soil with the application of G. pannorum and P. carneus were comparable to those obtained with the fungal strains currently used in organic fertilizers (Morales et al., 2007; Mittal et al., 2008; Kaewchai et al., 2009), making them good candidates for field-level testing. However, despite the increase of available phosphorus in the soil, the tested fungi did not stimulate plant growth. Growth promotion is commonly considered an indirect indicator of phosphate solubilization by a microorganism (Dupponois et al., 2006; Kapri and Tewari, 2010). Nonetheless, these characteristics could be more related to the production of phytohormones and growth-promoting substances than to phosphorus solubilization (Narloch et al., 2002). A better indicator of the effect of phosphate solubilization on plants by a microorganism is to evaluate the variables related to phosphorus uptake, such as the numbers of flowers, fruits or seeds (Bashan et al., 2013; Viruel et al., 2014). We recorded a slight increase in the number of seeds in oat plants in the treatment with P. carneus, which may be directly related to the increase in available soil phosphorus (El-Azouni, 2008; Malviya et al., 2011). Conversely, although $G$. pannorum increased the available $\mathrm{P}$ in the soil (by up to $35 \%$ ), it did not stimulate oat plant seed production. Similar effects have been reported in chickpea plants grown in soil that had been inoculated with Aspergillus and Penicillium strains, which did not stimulate plant growth or seed production, even as they increased the amount of available phosphorus in the soil (Mittal et al., 2008). This effect could be related to the production of secondary metabolites that inhibited plant development, but further studies are needed to understand this phenomenon better (Patten and Glick, 2002). 
In addition to phosphate solubilizations, the two fungi that were tested in our study reduced the G. rostochiensis infestation level. In fact, Paecilomyces carneus nematicidal potential has already been shown in the field against G. rostochiensis (Lopez-Lima et al., 2013). This fungus has been the subject of a patent application (WO 2012/148251 A2) based on its nematicidal properties. The study of microorganisms that provide more than one benefit for the development of crop plants is important (Li et al., 2015). In this sense, the dual activity recorded for the two tested fungi represents an ecologically safe strategy for enhancing the nutrition supply and plant parasitic nematode control, and both fungi tested in our study could be integrated into sustainable agriculture practices.

\section{Conclusions}

The fungal species examined in this study increased the amount of soluble P in PB medium containing both calcium and iron phosphate (hydroxyapatite and strengite) and reduced the G. rostochiensis infestation level. This is the first report in which the ability of G. pannorum to solubilize phosphate has been tested. The two fungal species solubilized similar quantities of calcium phosphates in vitro. Geomyces pannorum was more efficient at solubilizing iron phosphates in vitro. Both $G$. pannorum and P. carneus have the ability to increase the amount of available soil phosphorus. Further studies should focus on the effect of this ability on crop yield when these fungal strains are inoculated into agricultural soils.

\section{Acknowledgments}

This study was conducted in the laboratory of Fungal Biodiversity and Systematics at the Instituto de Ecología, A.C., and it represents part of the results obtained during project 0174936 , which was funded by the Sector Innovation Fund of the Consejo Nacional de Ciencia y Tecnologia(CONACyT). The first author is grateful to CONACyT for a fellowship (350769/238333) that was used to support her postgraduate studies at the Universidad Autónoma del Estado Mexico. The authors would also like to thank Ariadna Martinez Virues for assistance with the phosphorus detection in the liquid medium. Finally, we would like to thank Sandra Rocha, Ninfa Portilla and Lourdes Cruz for their technical assistance with soil physico-chemical analysis.

\section{References}

Abad, P., Gouzy, J., Aury, J.M., Castagnone-Sereno, P., Danchin, E.G.J., Deleury, E., Perfus-Barbeoch, L., Anthouard, V., Artiguenave, F., Blok, V.C. 2008. Genome sequence of the metazoan plantparasitic nematode Melodgyne incognita. Nat. Biotech. 26, 909-915.

Barroso, C.B., Nahas, E. 2005. The status of soil fractions and the ability of fungi to dissolve hardly soluble phosphates. Appl. Soil Ecol. 29, 73-83.

Bashan, Y., Kamnev, A.A., de-Bashan, L.E. 2013. Tricalcium phosphate is inappropriate as a universal selection factor for isolating and testing phosphate-solubilizing bacteria that enhance plant growth: a proposal for an alternative procedure. Biol. Fertil. Soils. 49, 465-479.

Bray, R.H., Kurtz, L.T. 1945. Determination of total, organic and available forms of phosphorus in soil. Soil Sci. 59, 39-45.

Chitwood, D.J. 2002. Phytochemical based strategies for nematode control. Annu. Rev. Phytopathol. 40, 221-249.

Chuang, C.C., Kuo, Y.L., Chao, C.C., Chao, W.L. 2007. Solubilization of inorganic phosphates and plant growth promotion by Aspergillus niger. Biol. Fertil. Soils. 43, 575-584. 
Coutinho, F.P., Felix, W.P., Yano-Melo, A.M. 2012. Solubilization of phosphates in vitro by Aspergillus spp. and Penicillium spp. Ecol. Eng. 42, 85-89.

Dorozhkin, S.V. 2011. Calcium orthophosphates. Occurrence, properties, biomineralization, pathological calcification and biomimetic applications. Biomatter. 1, 121-164.

Duponnois, R., Kisa, M., Plenchette, C. 2006. Phosphate-solubilizing potential of the nematophagous fungus Arthrobotrys oligospora. J. Plant Nutr. Soil Sci. 169, 280-282.

El-Azouni, I.M. 2008. Effect of phosphate solubilizing fungi on growth and nutrient uptake of soybean (Glycine max L.) plants. J. Appl. Sci. Res. 4, 592-598.

Fu, S.F., Sun, P.F., Lu, H.Y, Wei, J.Y., Xiao, H.S., Fang, W.T., Cheng, B.Y. Chou, J.Y. 2016. Plant growth-promoting traits of yeasts isolated from the phyllosphere and rhizosphere of Drosera spatula Lab. Fungal Biol. 120, 433-448.

Gudiño, M.E., de Abreu, L.M., Marra, L.M., Pfenning, L.H., Moreira, F.M.d.S. 2015. Phosphate solubilization by several genera of saprophytic fungi and its influence on corn and cowpea growth. J. Plant Nutrition. 38, 675-686.

Han, J., Jie, W.G., Cai, B.Y. 2014. Effect of phosphorus on the composition and accumulation of $7 \mathrm{~S}$ and $11 \mathrm{~S}$ globulin subunits during seed development of three soybean varieties. J. Soil Sci. Plant Nutr. 14, 769-782.

Hernández-Leal, T., Carrión, G., Heredia, G. 2011. Solubilización in vitro de fosfatos por una cepa de Paecilomyces lilacinus (Thom) Samsom. Agrociencia. $45,881-892$.

Jaffee, B.A. 1992. Population biology and biologicl control of nematodes. Can, J. Microbiol. 38, 359364.
Kaewchai, S., Soytong, K., Hyde, K.D. 2009. Mycofungicides and fungal biofertilizers. Fungal Divers. $38,25-20$.

Kapri, A., Tewari, L. 2010. Phosphate solubilization potential and phosphatase activity of rhizospheric Trichoderma spp. Braz. J. Microbiol. 41, 787-795.

Khan, M.S., Zaidi, A., Ahmad, E. 2014. Mechanismis of phosphate solubilization and physiological functions of phosphate-solubilizing microorganisms. In: M.S. Khan, A. Zaidi, J. Musarrat (eds.). Phosphate solubilizing microorganisms. Springer. Switzeland. pp: 31-62.

Li, J., Zou, C., Xu, J., Ji, X., Niu, X., Yang, J., Huang, X., Zhang, K.Q. 2015. Molecular mechanisms of nematode-nematophagous microber interactions: basis for biological control of plant parasitic nematodes. Annu. Rev. Phytopathol. 53, 67-95.

Li, Z., Bai, T., Dai, L., Wang, F., Tao, J., Meng, S., Hu, Y., Wang, S., Hu, S. 2016. A study of organic acid production in contrasts between two phosphate solubilizing fungi: Penicillium oxalicum and Aspergillus niger. Sci. Rep. 6, 25313.

Lopez-Lima, D., Sánchez-Nava, P., Carrion, G., Núñez-Sánchez, A.E. 2013. 89 \% reduction of a potato cyst nematode population using biological control and rotation. Agron. Sustain. Dev. 33, 425-431.

Malviya, J., Singh K., Joshi, V. 2011. Effect of solubilizing fungi and nutrient uptake of ground nut ( $\mathrm{Ar}$ achis hypogaea) plants. Adv. Biores. 2, 110-113.

Merbach, W., Deubel, A., Gransee, A., Ruppel, S., Klamroth, A.K. 2010. Phosphorus solubilization in the rhizosphere and its possible importance to determine phosphate plant availability in soil. A review with main emphasis on German results. Arch. Agron. Soil Sci. 56, 119-138. 
Mittal, V., Singh, O., Nayyar, H., Kaur, J., Tewari, R. 2008. Stimulatory effect of phosphate solubilizing fungal strains (Aspergillus awamori and Penicillium citrinum) on the yield of chickpea (Cicer arietinum L. cv. GPF2). Soil Biol. Biochem. 40, 718-727.

Morales, A., Alvear, M., Valenzuela, E., Castillo, C.E., Borie, F. 2011. Screening, evaluation and selection of phosphate-solubilising fungi as a potential biofertiliser. J. Soil Sci. Plant Nutr. 11, 89-103.

Morales, A., Alvear, M., Valenzuela, E., Rubio, R., Borie, F. 2007. Effect of inoculation with Penicillium albidum, a phosphate-solubilizing fungus, on the growth of Trifolium pratense cropped in a volcanic soil. J. Basic Microbiol. 47, 275-280.

Nahas, E. 1996. Factors determining rock phosphate solubilization by microorganisms isolated from soil. World J. Microb. Biot. 12, 567-572.

Narloch, C., Lopes de Oliveira, V., Ternes dos Anjos, J., Nunes Silva, F.G. 2002. Respotas da cultura do rabanete à inoculação de fungos solubilizadores de fosfatos. Pesquisa Agropecuaria do Brasil. 37, 841-845.

Nopparat, C., Jatupornpipat, M., Rittiboon, A. 2009. Optimization of the phosphate-solubilizing fungus, Aspergillus japonicus SA22P3406, in solidstate cultivation by response surface methodology. Kasetsart Journal: Natural Science. 43, 172-181.

Pandey, A., Das, N.B., Rinu, K., Trivedi, P. 2008. Phosphate solubilization by Penicillium spp. isolated from soil samples of Indian Himalayan region. World J. Microb. Biot. 24, 97-102.

Patten, C.L., Glick, B.R. 2002. Role of Pseudomonas putida indole acetic acid in development of the host plant root system. Appl. Environ. Microbiol. 68, 3795-3801.
R Core Team. 2013. R: A Language and Environment for Statistical Computing. R Foundation for Statistical Computing, Vienna, Austria. http:// www.R-project.org/.

Rinu, K., Malviya, M.K., Sati, P., Tiwari, S.C., Pandey, A. 2013. Response of cold-tolerant Aspergillus spp. to solubilization of $\mathrm{Fe}$ and $\mathrm{Al}$ phosphate in presence of different nutritional sources. ISRN Soil. Sci. http://www.hindawi.com/isrn/soil.science/2013/598541/

Schachtman, D.P., Reid, J.R., Ayling, S.M. 1998. Phosphorus uptake by plants: from soil to cell. Plant. Physiol. 116, 447-453.

Schoebitz, M., Ceballos, C., Ciampi, L. 2013. Effect of immobilized phosphate solubilizing bacteria on wheat growth and phosphate uptake. J. Soil Sci. Plant Nutr. 13, 1-10.

Sijmons, P.C. 1994. Parasitic strategies of root nematodes and associated host cell resposes. Annu. Rev. Phytopathol. 32, 235-259.

Sharma, S.B., Sayyed, R.Z., Trivedi, M.H., Gobi, T. A. 2013. Phosphate solubilizing microbes; sustainable approach for managing phosphorus deficiency in agricultural soils. Springer Plus 2, 587.

Sullivan, M.J., Inserra, R.N., Franco, J., MorenoLeheudé, I., Greco, N. 2007. Potato cyst nematodes: Plant host status and their regulatory impact. Nematropica. 37, 193-201.

Sundara, R., Sinha, M. 1963. Organisms phosphate solubilizers in soil. Indian J. Agr. Sci. 33, 272278.

Vera, D.F., Perez, H., Valencia, H. 2002. Aislamiento de hongos solubilizadores de fosfatos de la rizosfera de araza (Eugenia stipitata, Myrtaceae). Acta Biológica Colombiana. 7, 33-40. 
Viruel, E., Erazzú, L.E., Martínez Calsina L., Ferrero, M.A., Lucca, M.E., Siñeriz, F. 2014. Inoculation of maize with phosphate solubilizing bacteria: effect on plant growth and yield. J. Soil Sci. Plant Nutr. 14, 819-831.

Vyas, P., Rahi, P., Chauhan, A., Gulati, A. 2007. Phosphate solubilization potential and stress tolerance of Eupenicillium parvum from tea soil. Mycol. Res. 111, 931-938.

Wakelin, S.A., Warren, R.A., Harvey, P.R., Ryder, M.H. 2004. Phosphate solubilization by Penicillium spp. closely associated with wheat roots. Biol. Fertil. Soils. 40, 36-43.

Walpola, B.C., Yoon, M.H. 2012. Prospectus of phosphate solubilizing microorganisms and phosphorus availability in agricultural soils. A review. African J. Microbiol. Res. 37, 6600-6605.

Whitelaw, M.A. 1999. Growth promoting of plants inoculated with phosphate-solubilizing fungi. Adv. Agron. 69, 99-151.
Yasser, M.M., Mousa, A.S.M., Massoud, O.N., Nasr, S.H. 2014. Solubilization of inorganic phosphate by phosphate solubilizing fungi isolated from Egyptian soils. J. Biol. Earth Sci. 4, 83-90.

Yin, Z., Shi, F., Jiang, H., Roberts, D.P., Chen, S., Fan, B. 2015. Phosphate solubilization and promotion of maize growth by Penicillium oxalicum P4 and Aspergillus niger $\mathrm{P} 85$ in a calcareus soil. Can. J. Microbiol. 61, 913-923.

Zúñiga-Silva, J.R., Chan-Cupul, W., Kushk, P., Loera, O., Aguilar-López, R, Rodríguez-Vázquez, R. 2016. Effect of $\mathrm{Cd}^{+2}$ on phosphate solubilizing abilities and hydrogen peroxide production of soil-borne micromycetes isolated from Phragmites australis-rhizosphere. Ecotoxicology 25, 367-379. 